\title{
Strategies for mitigation of progressive collapse of corner panels in reinforced concrete buildings
}

\author{
O. A. Mohamed \\ University of Hartford, \\ Department of Civil, Biomedical and Environmental Engineering, \\ West Hartford, CT, USA
}

\begin{abstract}
Studies have shown that loss of exterior columns at any floor level of a framed structure building results in higher stresses and larger deformations at the elements of a panel located at the corner of the building and supported by exterior columns compared to panels supported by interior columns. Beams supporting interior or exterior panels can be designed to bridge over a failed column, which may not possible for beams supporting corner panels. As a result, corner panels of framed reinforced concrete buildings are particularly susceptible to progressive collapse. Since design of structures to prevent progressive collapse entirely may not be realistic for most buildings, it is desirable to adopt selected measures to achieve a desired level of protection. Most building codes and design guides permit certain damage levels for interior and exterior panels. For corner panels, permissible damage limits can be met by adjusting the spans from the corner column to the first exterior columns. When adjusting spans of beams is not architecturally desirable, a strategy to protect the exterior column must be adopted. Possible options include 1) designing steel bracing to support the additional load from a failed column, 2) designing edge panels and supported beams to cantilever the full length after the loss of column, and 3) stiffening the columns for code specified pressure levels. The first two options are discussed in this paper. A case study is presented in this paper to demonstrate these two options.
\end{abstract}

Keywords: progressive collapse, reinforced concrete, building codes, lateral bracing. 


\section{Introduction}

According to the American Society of Civil Engineers (ASCE), progressive collapse is defined as "the spread of an initial local failure from element to element, eventually resulting in the collapse of an entire structure or a disproportionately large part of it."

Building codes and design standards in many parts of the world incorporate certain provisions to minimize the potential for progressive collapse and/or mitigate its effects. A review of the progressive collapse provisions in certain building codes and design standards was given by Mohamed [1]. UFC 4-023-03 [2], is a progressive collapse design guide published by the United States Department of Defense and is applicable for buildings consisting of three stories or more. The provisions of UFC 4-023-03 are emphasized in this paper because this design guide contains the most prescriptive requirements for design against progressive collapse compared to the current building codes and design standards in the United States. UFC 4-023-03 will be referred to in this paper as UFC.

UFC requires varying degrees of rigor on structural analysis and design requirements for progressive collapse mitigation, based on the desired level of protection. The most rigorous requirements are for structures assigned to categories Medium Level of Protection (MLOP) and High Level of Protection (MLOP). For framed-structures, the flexural resistance to progressive collapse is investigated using the Alternate Path (AP) method, which involves the notional removal of selected exterior and interior columns and investigating the capability of the remaining structure to bridge over the removed columns. The notional removal of an interior column, during an AP investigation requires the strengthening of the overarching beams and other structural elements. The AP method is also described in ASCE 7-05 [5], which categorizes the method as one of the two Direct Design Methods. According to section 3-2.3.2.2 of UFC, AP analysis of internal columns is only needed for designated columns in the ground floor or parking area floor. For external columns, an AP investigation is required for each column at all floor levels per section 3-2.3.2.1 of UFC. As such, progressive collapse design for MLOP and HLOP could be a very time consuming process. The removal of a corner column may result in long cantilevers, especially when the area of the corner panels supported by the column are larger the permissible damage limit. The effects of beam dimensions, reinforcement ratio and other parameters on the response of corner beams and columns was investigated by Hansen et al [3].

According to section 3-2.4.2 of UFC, for linear and nonlinear static analyses, the following load combination should be applied to the bays adjacent to the removed column and to all of the corresponding bays in the floors above the removed column.

$$
2.0[(0.9 \text { or } 1.2) D+(0.5 L \text { or } 0.2 S)]+0.2 W
$$

where,

$\mathrm{D}=$ Dead load

$\mathrm{L}=$ Live load 
$\mathrm{W}=$ wind Load

$\mathrm{S}=$ Snow load

The rest of the structure is loaded with the following load combination.

$$
(0.9 \text { or } 1.2) D+(0.5 L \text { or } 0.2 S)+0.2 W
$$

The 2.0 magnification factor used for the bays above the removed column account for the fact that these bays will be subjected to the dynamic effects of column removal as well as debris from the upper floors. The load combinations in eqn. (1) and eqn. (2) are investigated in this paper to test a corner column in a case study reinforced concrete building.

For all levels of protection and with all analysis methods, the possibility of loss of lateral support to columns at the floor level during a progressive collapse event must be considered in the analysis models. Therefore, columns will be modelled with heights that twice the story heights. This is implemented in this paper for the columns of the structure in the AP investigation model.

\section{Damage limits}

The objective of an AP progressive collapse analysis is not to inhibit damage but rather to limit its extent. According to UFC section 3-2.6.1, the maximum permissible area damage from an AP investigation of an external column, is smaller of $750 \mathrm{ft}^{2}$ or $15 \%$ of the floor directly supported by the notionally removed column. For framed structures, the beams and columns supporting the floor areas are also subject to maximum deformations/forces/moments.

According to UFC Table 3-1, when the maximum bending moment is reached in an element that is not designed to support loads beyond the peak moment, that element should be removed from the model, before the analysis is continued. If the element is designed and detailed to support moments beyond the peak moment, a hinge is located where the peak moment is reached and analysis is continued. In this paper, elements supporting a corner panel will be considered to fail when the peak moment is reached. When this limitation is imposed, the deformations associated with post-peak response will not be considered in the model.

Deformation limits of reinforced concrete flexural members are described in UFC Table 4-4. Different rotation limits are given depending on the desired level of protection. That deformation limit is expressed as maximum rotation in degrees, depends whether on tension membrane resistance is considered and whether shear reinforcement is provided, and whether the sections are singly reinforced or doubly reinforced. In this paper, tension membrane for corner slabs is ignored, the beams are doubly reinforced, and shear reinforcement is provided. In this case, the maximum permissible flexural rotation is $\theta=4^{\circ}$. 


\section{Case study}

To examine some of the UFC requirements for the removal of corner columns in an AP investigation, a case study reinforced concrete, shown in fig. 1, is analyzed and designed. The structure is a 6-story moment-frame building. Each floor consists of five 28 -ft-span panels. All columns are $13.5 \mathrm{ft}$ tall, equal to floor heights. The area of the corner panels is $784 \mathrm{ft}^{2}$, which exceeds the area damage limit based on UFC criteria. The corner panel is considered to fail if the supporting beams fail during the AP analysis. Therefore, the objective of the analysis and design is to reduce the potential for collapse of this area and the beams supporting it. Analyses were performed using SAP2000 software, produced by Computers and Structures, Inc.

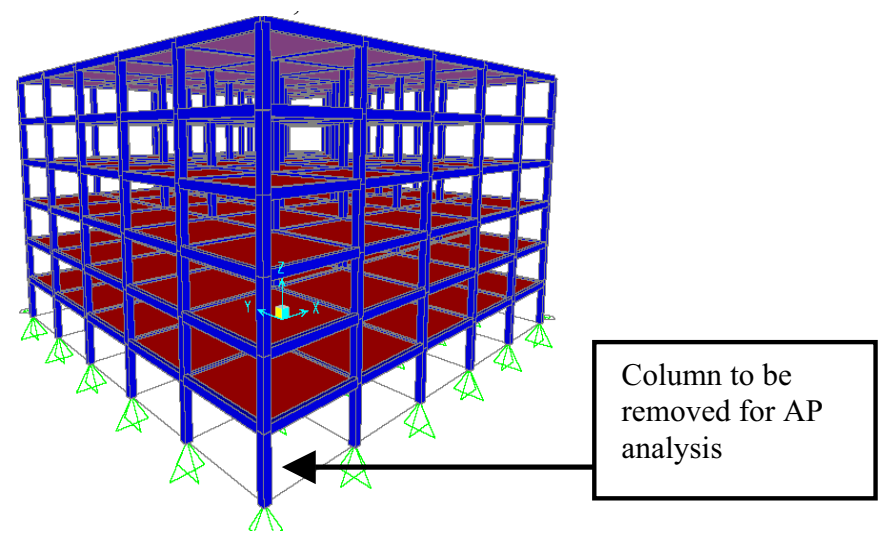

Figure 1: $\quad$ Case study reinforced 6-story moment-frame reinforced concrete building.

Before the AP progressive collapse investigation is performed, the building is analyzed and designed according to ACI 318-05 [5] load combinations and design provisions. The service gravity and wind loads applied to the structure are as follows:

Gravity loads:

Dead load from normal weight concrete (150 pcf).

Superimposed dead load $=35 \mathrm{psf}$.

Live load $=50 \mathrm{psf}$.

Wind load:

External cladding $=200$ plf.

Wind speed $=100 \mathrm{mph}$,

Exposure type: B.

Wind load calculations are based in ASCE 7-05 [5].

Member dimensions that met ACI 318-05 force/deformation provisions are: Beams $=14$ inches $\times 24$ inches; Columns $=24$ inches $\times 24$ inches. 


\subsection{AP progressive collapse models}

In this section, the potential for progressive collapse of the structure in fig. 1 is investigated when a corner column is notionally removed. The removed column, and AP investigation loads are shown in fig. 2. The story heights were doubled to $27 \mathrm{ft}$ as required in UFC section 2-2.1.

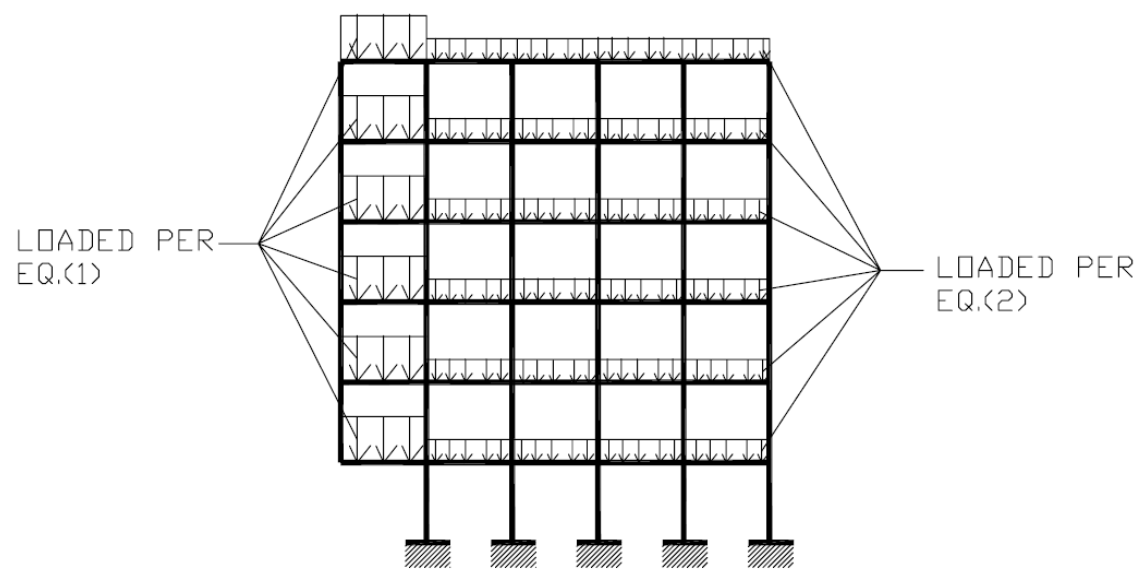

Figure 2: Loading on a typical frame for AP investigation. A corner column at the ground floor level is notionally removed.

As a result of the load combinations in eqn (1) and (2), 9 beams failed due to flexure $\left(M_{u}>\phi M_{n}\right)$. All of the failed beams were in the building perimeter supporting the panel directly above the removed column from the first floor to fifth floor. The rest of the structure further from the removed column remained intact. To resolve the problem, perimeter beam dimensions were increased from 12 inches x 24 inches to 16 inches x 24 inches while all other members were kept unchanged. All members now pass the ACI318-05 and UFC flexural and shear requirements. Maximum rotations occurred in the perimeter beams of the corner panel but remained less than $\theta<4^{\circ}$. The maximum deflection is shown fig. 3. As would be expected, corner panel deflection increased slightly from floor to floor with the maximum deflection at the roof level.

Increasing the perimeter beam dimensions so they can cantilever the entire span when corner column is removed is only feasible up to certain lengths. The longer the spans at the corner panels, the larger the deflection at the ends of the cantilevered beams. Furthermore, if the design load combination is exceeded and the cantilever fails, no alternate load path is available.

Since ductility is an important consideration in post-peak response of the structure, using steel bracing at corner panels to provide alternate load paths is beneficial. Lateral bracing also reduces lateral drift. A variety of steel bracing configurations are possible, consider for example the inverted- $\mathrm{V}$ configuration in fig. 4. 


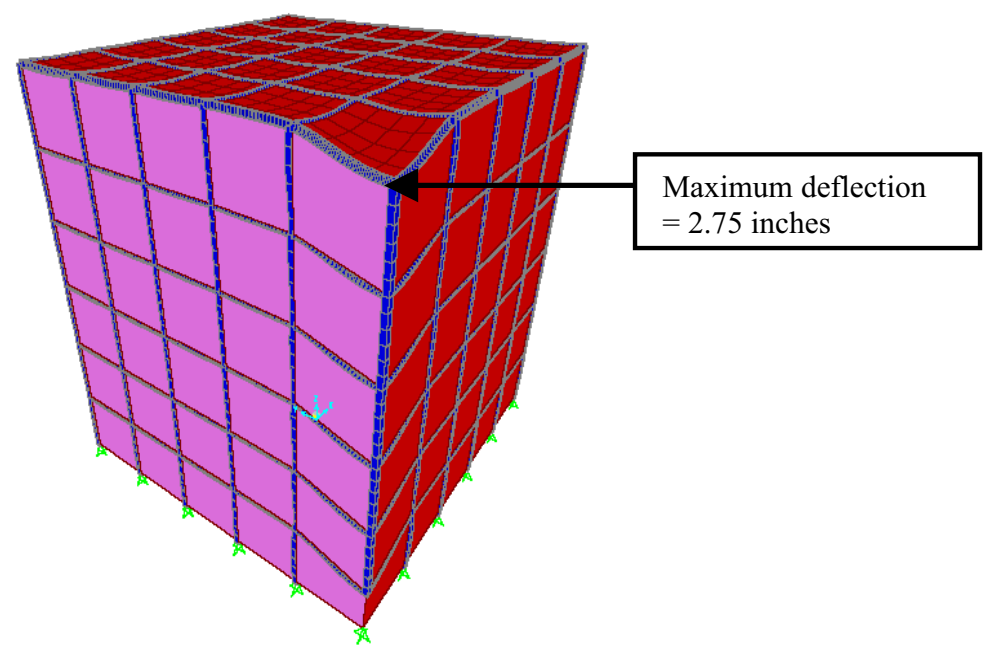

Figure 3: $\quad$ Deformed shape due to the load combinations shown in fig. 2.

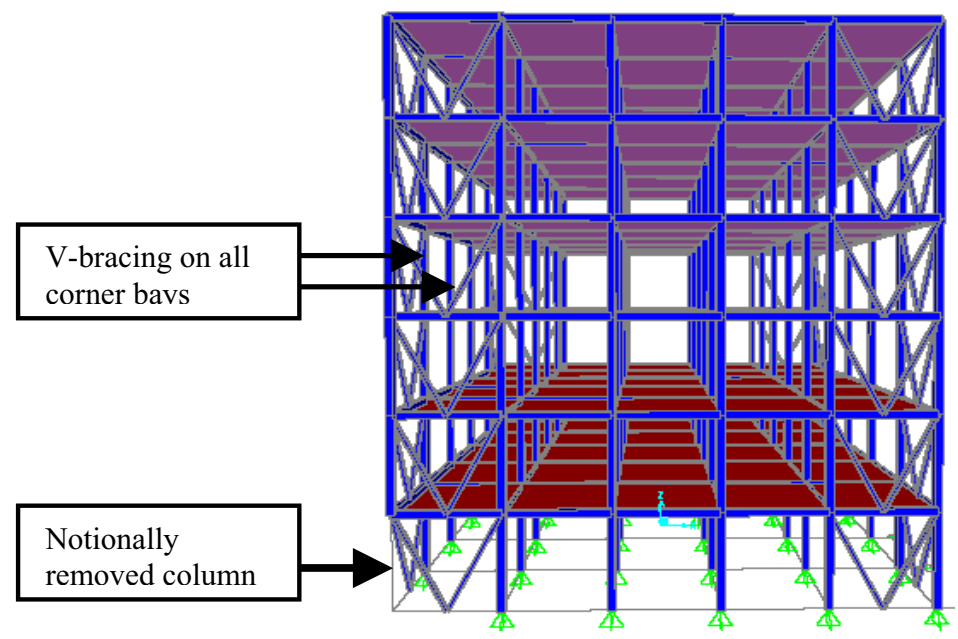

Figure 4: V-bracing at corner bays to resist lateral loads and provide and alternate path for corner columns.

The steel members of the bracing configuration shown fig. 4 are W12 x 65 which were designed according to the American Institute of Steel Construction (AISC) LRFD method [6]. All member dimensions for this AP model were kept the same as for the AP model without bracing as described below:

Interior beams: 12 inches $x 24$ inches.

Perimeter beams: 16 inches $x 24$ inches

Exterior and interior Columns: 24 inches x 24 inches. 
For the braced system, 9 beams failed but unlike the unbraced model, they failed due to high shear stresses caused by torsion moments. The torsion moments that resulted in torsion shear failure are shown in fig. 5. Clearly, where the corner column was removed torsion moments generated in the beams supporting the corner panel were higher than the torsion moments in the corresponding locations of this symmetric structure. According to UFC Table 31 , a member that fails the shear stress criteria should be removed from the model and analysis is continued without it. However, for this corner panel, removing the two supporting perimeter beams leads to unsupported panel and the collapsed area as discussed earlier in this paper exceed the maximum UFC damage limit. Therefore, the dimensions of perimeter beams were increased to 18 inches x 24 inches (12.5\% increase in width). The dimensions of all other beams and columns were kept unchanged because they did not fail. Analysis and redesign shows that the change to perimeter beams is satisfactory and all elements pass UFC force and deformation requirements.

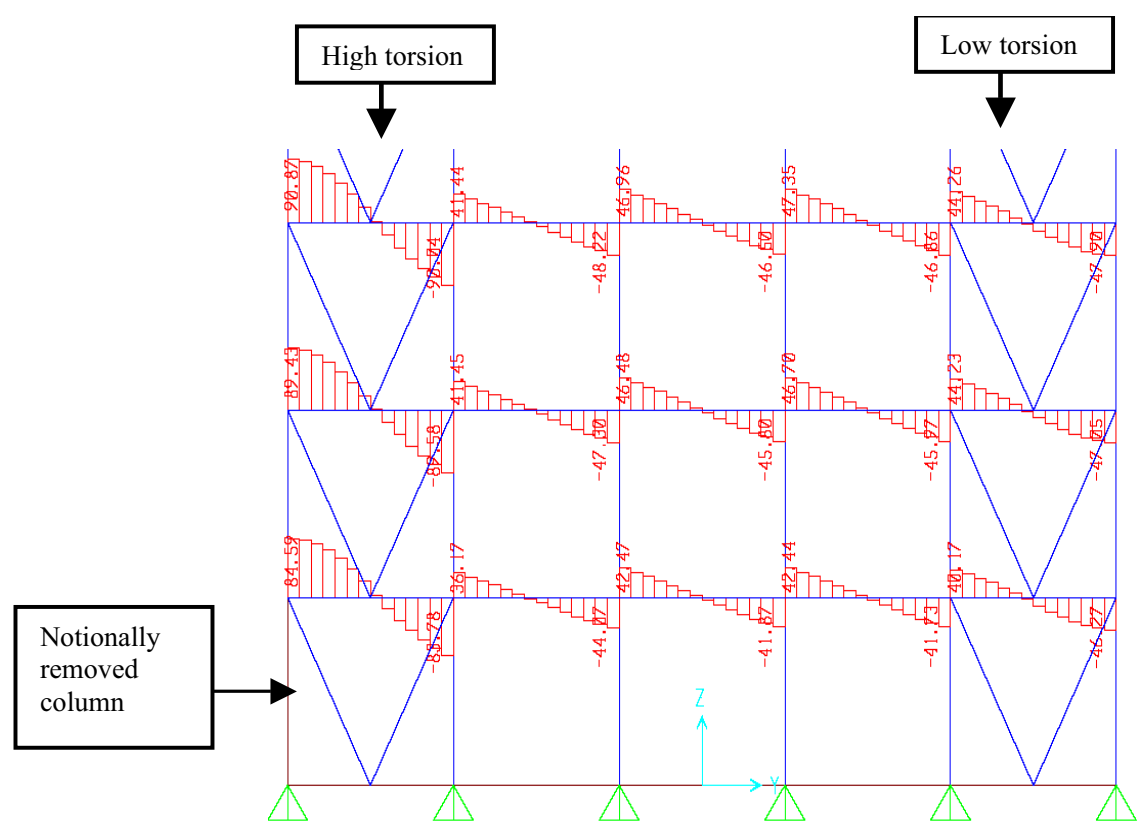

Figure 5: Torsion diagram on a on a front elevation that contains bracing showing larger twisting moments (kip.ft) in bays where a column is notionally removed.

Steel bracing is a better alternate path in progressive collapse mitigation efforts than allowing beams to cantilever for a long distance despite the likely additional cost associated with lateral steel bracing. The argument for lateral steel bracing as part of the alternate gravity load path is further justified 
economically when lateral bracing is needed to resist lateral forces in the original design or to control drift. Furthermore, a bracing reduces the final deformation amplitudes in a structure subjected to loss of column as shown in fig. 6.

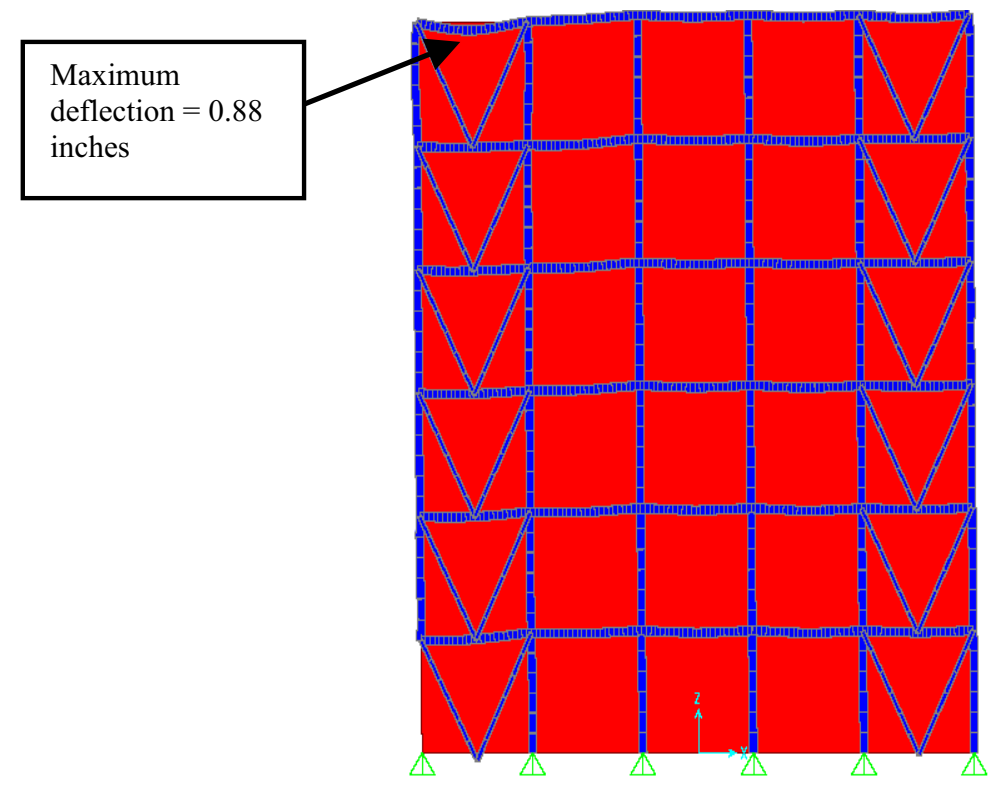

Figure 6: Deformed shape of V-braced structure under AP load combinations.

\section{Summary and conclusion}

- Consideration of three-dimensional effects during an AP progressive collapse investigation is crucial. Torsional moments, clearly predictable during a three-dimensional analysis, can cause shear stresses to exceed member capacities. They will not be present in a two dimensional analysis unless they considered explicitly.

- To meet force and deformation demand of beams during an AP progressive collapse investigation of a moment frame structure, beams supporting corner columns can be designed to cantilever the full span while satisfying flexural and deformation limits specified by UFC. However using lateral bracing at corner bays helps provide a more reliable alternate load path in the event of loss of a primary load carrying member. Furthermore, the final deformations of a structure subjected to loss of a primary load-carrying member are smaller if the structure is braced that if it is not. Using lateral bracing is particularly advantageous to provide more control over lateral drift by considering its stiffness during the regular part of the design, which does not involve progressive collapse investigation. 


\section{References}

[1] Mohamed, O. A. Progressive Collapse of Structures: Annotated Bibliography and Comparison of Codes and Standards. Journal of Performance of Constructed Facilities - ASCE, 20(4), pp. 418-425, 2006.

[2] Unified Facilities Criteria - Design of Buildings to Resist Progressive Collapse (UFC 4-023-03); United States Department of Defense, 2005.

[3] Hansen, E., Wong, F., Lawver, Oneto, R., Tennant, D., and Ettouney, M. Development of an Analytical Database to Support Fast Running Progressive Collapse Assessment Tool. Proc. of Metropolis \& Beyond the 2005 ASCE Structures Congress, New York, New York.

[4] ACI 318-5 Building Code Requirements for Structural Concrete and Commentary; American Concrete Institute, Farmington Hills, Michigan.

[5] ASCE/SEI 7-05 Minimum Design Loads for Buildings and other Structures; American Society of Civil Engineers, Reston, Virginia.

[6] Manual of Steel Construction - LRFD, $3^{\text {rd }}$ Ed.; American Institute of Steel Construction, Chicago, Illinois. 